\title{
O papel dos agentes de recursos humanos na implementação da Política de Atenção à Saúde e Segurança do Trabalho do Servidor Público Federal (PASS)
}

\author{
José Marçal Jackson Filho \\ Fundação Jorge Duprat Figueiredo de Segurança e Medicina do Trabalho (Fundacentro)
}

Tarsila Baptista Ponce

Fundação Jorge Duprat Figueiredo de Segurança e Medicina do Trabalho (Fundacentro)

Os agentes de recursos humanos $(\mathrm{RH})$ das instituições públicas federais têm a responsabilidade de intermediar os afastamentos por problemas de saúde dos servidores junto ao Subsistema Integrado de Atenção à Saúde dos Servidores (SIASS), instituído pela PASS desde 2009. O objetivo deste estudo é analisar o trabalho desses agentes e sua margem de ação diante das prescrições da PASS e dos meios oferecidos pelo SIASS. Para tanto, foram realizadas análise documental e entrevistas semiestruturadas com dez agentes de RH de sete instituições da cidade de São Paulo, utilizando-se análise de conteúdo do tipo temática para tratamento do material. Os resultados mostram que o trabalho dos agentes está voltado, sobretudo, às práticas de controle dos afastamentos dos servidores ao trabalho, ocorrendo em serviços que não dispõem de recursos e estrutura suficiente. Desse modo, a PASS tem sido pouco efetiva para enfrentar os problemas de saúde dos servidores.

Palavras-chave: gestão de pessoas, seguridade social, agente público, política de saúde

[Artigo recebido em 26 de novembro de 2015. Aprovado em 19 de julho de 2016.] 
El papel de los agentes de recursos humanos en la aplicación de la Política de Atención en Salud y Seguridad del Trabajo del Funcionario Público Federal (PASS)

Los agentes de recursos humanos $(\mathrm{RH})$ de las instituciones públicas federales tienen la responsabilidad de mediar los alejamientos de los servidores públicos con problemas de salud junto al Subsistema Integrado de Atención a la Salud del Servidor (SIASS), establecido por la PASS (Política de Asistencia a la Salud del Servidor) desde el año de 2009. El objetivo de este estudio es investigar el trabajo de estos agentes y sus posibles acciones delante de los requisitos de la PASS y de los medios ofrecidos por el SIASS. Por lo tanto, se llevó a cabo el análisis de documentos y entrevistas semi-estructuradas con diez agentes de RH de siete instituciones de la ciudad de São Paulo, fue utilizado el método de análisis del contenido de tipo temático para tratar el material de las entrevistas. Los resultados muestran que el trabajo de los agentes está orientado, sobretodo, a las prácticas de control de los alejamientos de los servidores del trabajo, ocurriendo in servicios que no tienen recursos y estructura suficiente. De este modo, la PASS ha sido poco efectiva en el combate a los problemas de salud de los servidores.

Palabras clave: gestión del personal, seguridad social, funcionario público, política de salud

The role of human resources agents in the implementation of the Civil Servant Occupational Health and Safety Care Policy (PASS)

Human resources agents of federal public institutions have the role of mediate the formalization of sick leave related to health problems with the Civil Servants Safety and Health Care Integrated Subsystem (SIASS), implemented by PASS since 2009. The aim of this research is to analyze the work practices of these agents and their latitude of action within PASS requirements and the means available by SIASS centers. A documental data analysis was realized, semi-structured interviews were conducted with ten human resources agents from seven institutions located in São Paulo and a thematic content analysis was realized to treat interviews material. The results show that the agents' work practices are mainly directed to the control of servant's sick leaves, situated in services with lack of resources and of structure. In this way, PASS has not been so effective to face servant's health problems.

Keywords: personnel management, social security, public agent, health policy 


\section{Introdução}

Nos últimos vinte anos, os servidores públicos vivenciam, assim como os demais trabalhadores, o avanço tecnológico e as novas formas de gestão que contextualizam as mudanças ocorridas no mundo do trabalho (RIBEIRO; MANCEBO, 2013).

Nesse período, o serviço público passou por reformas administrativas baseadas nas tendências do setor privado, com a intenção de acompanhar a aceleração advinda do processo de globalização e internacionalização da economia (PAULA, 2005). Entretanto, as mudanças propostas se depararam com os sérios problemas econômicos, com a ineficiência das políticas públicas e algumas características incorporadas ao longo da nossa história, como a cultura patrimonialista e os princípios burocráticos arraigados que se contrastaram, em determinado momento, com os novos modos de gestão pública (MARCELINO, 2003; COSTA, 2006).

Além disso, na década de 1990, quando essas reformas vieram a se intensificar, os servidores passavam por um período de desmotivação devido aos insucessos das reformas anteriores, às indefinições na carreira, às limitações estruturais que se perpetuavam, assim como aos escândalos de corrupção que desvalorizaram e fragilizaram a imagem do funcionalismo, tornando o cenário do serviço público inoportuno para mudanças (MARTINS, 1997; ABRUCIO, 2007; RIBEIRO; MANCEBO, 2013).

Em meados da primeira década dos anos 2000, os problemas de saúde e as aposentadorias por invalidez entre os servidores surgem com mais força (CARneIRo, 2011). Pesquisas realizadas nesse sentido demonstraram o crescente adoecimento com o predomínio dos problemas relacionados a transtornos mentais, musculoesqueléticos e às neoplasias malignas (CARNEIRO, 2006; SALA et al., 2009; CUNHA; BLANK; BOING, 2009).

A criação da Política de Atenção à Saúde e Segurança do Trabalho do Servidor Público Federal (PASS) foi anunciada em decorrência dessa realidade, com intuito de consolidar ações na área da saúde e segurança no trabalho dos servidores públicos federais (BRASIL, 2010b), em meio à diversidade de práticas ${ }^{1}$ - e "não práticas" nesse campo, e de sanar o relevante número de aposentadorias por invalidez e adoecimentos constatados entre essa categoria profissional.

\footnotetext{
${ }^{1}$ Diante desse contexto, instituições públicas federais, como o Instituto Brasileiro de Geografia e Estatística (IBGE) e a Universidade Federal do Rio de Janeiro (UFRJ), iniciaram um processo para reestruturar ações internas já existentes voltadas à área da saúde dos seus servidores. O IBGE inseriu as ações destinadas à saúde dos trabalhadores em sua política de recursos humanos, que fazia parte do planejamento estratégico da instituição. A UFRJ formou um grupo de trabalho com participação do sindicato para discutir e elaborar uma proposta sobre um programa de saúde do trabalhador, resultando, em 2003, na Política de Saúde Integral do Corpo Social da UFRJ. Em decorrência desse trabalho, a UFRJ foi convidada pelo Ministério do Planejamento, Orçamento e Gestão (MPOG) a colaborar na construção da política nacional para o servidor público (ANDRADE, 2009).
} 
Como estratégia para implementação das ações e dos projetos da PASS, em 2009, foi criado o Subsistema Integrado de Atenção à Saúde do Servidor (SIASS) (BRASIL, 2010b), que tem como objetivo "coordenar e integrar ações e programas nas áreas de assistência à saúde, perícia oficial, promoção, prevenção e acompanhamento da saúde dos servidores" (BRASIL, 2009a).

Nesse contexto, entre as peculiaridades do serviço público e o desafio de implementar ações nesse campo propostas na política, trabalham os servidores da área de recursos humanos $(\mathrm{RH})$, os agentes de $\mathrm{RH}$, como os denominamos. Eles são responsáveis pela atividade meio das instituições, prestam serviço ao público interno, vivenciam no dia a dia as contradições decorrentes do duplo compromisso de trabalho com as pessoas e com as metas e as regras estabelecidas (LACOMBE; BENDASSOLLI, 2004).

No âmbito das instituições públicas, os agentes de RH são os interlocutores no encaminhamento e acompanhamento dos problemas de saúde dos servidores, pois intermediam a formalização dos afastamentos através da perícia médica realizada pela unidade do SIASS. Apesar das atribuições dos agentes de RH no trabalho de intermediação estarem descritas apenas indiretamente nas orientações e normativas², esses profissionais são atores importantes na realização das ações de saúde da PASS, em especial na promoção da saúde, da segurança e da qualidade de vida dos servidores (BRASIL, 2010b), devendo contar com apoio das unidades do SIASS.

Carneiro $(2006,2011)$ defende que a saúde do servidor público é uma questão para a gestão de pessoas, devendo estar sob a tutela da administração de recursos humanos, não do setor da saúde (secretarias ou ministério), pois se constitui em espaço provido de contato institucional ampliado e recursos específicos para lidar com essas questões. Destaca o importante papel do agente de $\mathrm{RH}$ no trabalho voltado à saúde do servidor, considerando que o mero encaminhamento à perícia médica resultaria apenas no controle dos absenteísmos.

Todavia, diante das contradições que vivencia no cumprimento dos regramentos imposto pelos modelos de $\mathrm{RH}$, nem sempre adequados à realidade das instituições, e, ainda, pelos impasses da administração pública, o agente encontra indefinições quanto a seu papel profissional.

Diante da responsabilidade que possuem em atender, ouvir e escutar os servidores no momento em que esses se encontram mais ou menos fragilizados, conforme o caso, os agentes de RH precisam estar preparados, tanto em relação às normativas prescritas pela PASS, quanto à forma de agir, ou seja, precisam saber

\footnotetext{
${ }^{2}$ A previsão legal para esse trabalho consta na Portaria no 1.397, de 10/08/2012 (BRASIL, 2012): “Art. 10. Compete aos órgãos e entidades partícipes do acordo de cooperação técnica, conjuntamente, na forma descrita no artigo 4을 desta Portaria: [...] IX - encaminhar os casos necessários para avaliação na unidade do SIASS; [...]".
} 
identificar e encaminhar os casos que assim o requerem, mantendo a ética e os cuidados em relação ao sigilo.

Mas, como afirmam Cunha, Blank e Boing (2009, p. 234), "na administração pública, a preocupação com os custos gerados pelo absenteísmo-doença por vezes supera a significação do processo adoecimento-afastamento do trabalho, dando ênfase às políticas de controle de benefícios". Como conciliar essa pressão pelo controle e a necessidade de dar assistência aos servidores adoecidos e de contribuir com a prevenção? Esse dilema parece estar no centro das preocupações dos agentes de $\mathrm{RH}$, cujo trabalho pretende-se compreender.

O objetivo deste estudo é, portanto, analisar o trabalho dos agentes de RH na intermediação entre os servidores e a unidade do SIASS, suas condições de trabalho, suas possibilidades de ação diante das limitações institucionais e das contribuições da unidade do SIASS localizada na cidade de São Paulo.

\section{Metodologia}

A pesquisa teve enfoque qualitativo, de caráter exploratório, desenvolvida por meio de análise documental e de entrevistas visando realizar análise do trabalho dos agentes de $\mathrm{RH}$, ou seja, compreender as condições de trabalho, os impedimentos e as possibilidades de ação presentes na atividade de trabalho.

Conduzimos a pesquisa tendo como referencial os elementos das abordagens teóricas que tratam da atividade de trabalho (GUÉRIN et al., 2001) e do poder de agir dos sujeitos na atividade de trabalho (CLOT, 2010). Para Clot (2010), ao realizar a atividade, o indivíduo vai além do prescrito, desenvolve seu poder de agir, dando sentido e eficiência à ação, conforme as possibilidades e/ou impossibilidades que se apresentam no real da atividade. O trabalho das pessoas, muitas vezes, encontrase impedido por diversos fatores ligados a critérios de gestão e de organização (SZNELWAR; MASCIA; BOUYER, 2006). Sob essa perspectiva, buscamos evidenciar a margem de ação dos agentes de $\mathrm{RH}$, os meios e recursos disponíveis e o agir nas situações de trabalho.

Em primeiro lugar, a análise documental foi realizada a fim de descrever e caracterizar as exigências formais que determinam as escolhas dos agentes de RH. Como parte da prescrição do trabalho dos agentes de $\mathrm{RH}$ se encontra na política e nos diversos documentos publicados, faremos apresentação sucinta sobre a PASS e as atribuições das unidades do SIASS. Dessa forma, pode-se ter uma visão das exigências formais que determinam as escolhas e ações nas atividades de intermediação. 
Em segundo lugar, foram feitas entrevistas com agentes de $\mathrm{RH}$, cujo critério de participação foi realizar o trabalho de atendimento ao servidor com a finalidade de formalizar os afastamentos por motivo de saúde, sejam dele mesmo ou de pessoa da família, por meio de perícia ou junta médica a ser realizada na unidade do SIASS.

Os agentes entrevistados pertencem aos órgãos públicos federais que compõem o primeiro Acordo de Cooperação Técnica (BRASIL, 2011) firmado com a unidade do SIASS localizada na cidade de São Paulo. Foram excluídos dois, dos 10 órgãos públicos que fazem parte do acordo: um, do qual a pesquisadora faz parte; e a instituição sede da unidade do SIASS, por não ter profissional que realiza o trabalho de intermediação. Um dos agentes de RH convidados, pertencente a uma das instituições partícipes do acordo de cooperação, não retornou os contatos realizados via telefone e correio eletrônico. Esse agente justificou por telefone a dificuldade de reservar um horário para a entrevista proposta devido ao excesso de trabalho.

Desse modo, realizamos entrevistas semiestruturadas com 10 agentes de RH pertencentes a sete órgãos públicos federais localizados na cidade de São Paulo, todos atendidos pela mesma unidade do SIASS.

Entrevistas semiestruturadas favorecem utilizar roteiro "construído de forma que permita flexibilidade nas conversas e a absorver novos temas e questões trazidas pelo interlocutor", com início, amplitude e profundidade no processo de comunicação (MıNAYo, 2010, p. 191).

O roteiro de entrevista foi elaborado contendo os seguintes eixos: o contexto/ circunstância do trabalho, a PASS, a intermediação e o papel dos agentes de RH.

Para tratamento do material coletado nas entrevistas, baseamo-nos nas orientações do método de análise de conteúdo. Utilizamos a técnica de análise temática, que tem como enfoque a identificação dos temas e a extração das características associadas (BARDIN, 2011).

Realizamos as transcrições de todas as entrevistas e, posteriormente, insistimos na leitura flutuante de cada uma delas, buscando retomar as hipóteses e os objetivos iniciais, aprofundar na compreensão e interpretação do conteúdo (MıNAYO, 2010).

Da exaustiva leitura e análise das transcrições, encontramos repetições temáticas que foram se desdobrando até serem transformadas em categorias, utilizadas para agrupar as subcategorias temáticas.

Inicialmente, as categorias temáticas resultantes da nossa análise se pautaram na identificação dos agentes de RH: quem são, onde trabalham, com quem trabalham e que atividades realizam. Posteriormente, chegamos ao trabalho de intermediação: o contexto, o papel desempenhado e as contribuições da unidade do SIASS. Por 
fim, consideramos as evidências dos impedimentos, das contrariedades e das ambiguidades presentes no trabalho de intermediação.

\section{Resultados}

\section{A Política de Atenção à Saúde e Segurança do Trabalho do Servidor Público Federal (PASS)}

Em meio às diversas reformas administrativas, mudanças organizacionais e aplicação dos modelos e das ferramentas de gestão, os adoecimentos e as aposentadorias por invalidez começaram a emergir no serviço público. A problemática dos adoecimentos entre os servidores se deparou com a ausência de diretrizes para lidar com as questões de saúde, pois, apesar de algumas poucas orientações prescritas, naquele momento nada havia sido implantado para que os assuntos referentes à saúde e à segurança dos servidores pudessem ser encaminhados (CARNEIRO, 2011).

Foi então, diante do cenário constatado, que a administração pública federal (APF) chegou ao consenso sobre a necessidade de estabelecer uma política para a realização das ações e dos encaminhamentos de saúde entre os servidores, tendo delegado ao MPOG essa responsabilidade.

\section{Breve histórico do surgimento da PASS}

Com a finalidade de identificar as razões do aumento das aposentadorias por invalidez e dos afastamentos do trabalho por motivo de saúde e propor ações necessárias para sua solução, o MPOG criou, em 2003, o Comitê Gestor de Atenção a Saúde do Servidor (CGSS), como parte da estrutura interna da sua Secretaria de Recursos Humanos (SRH/MP) (INVESTIMENTO..., 2005) ${ }^{3}$.

Como primeira iniciativa, a CGSS realizou, entre os anos de 2003 e 2004, um levantamento nos órgãos da APF com o objetivo de identificar como estavam sendo tratadas as questões de saúde e segurança entre os servidores públicos federais ${ }^{4}$.

Nesse levantamento, ficou constatado que, para atender as normativas, cada órgão da APF executava as ações de forma diferenciada, sendo que alguns haviam estruturado seus próprios serviços de saúde e outros não haviam realizado nenhuma iniciativa. A partir desse diagnóstico, iniciou-se a elaboração de uma

\footnotetext{
${ }^{3}$ Essa matéria foi publicada no boletim Contato. O site www.servidor.gov.br no qual o boletim Contato estava disponível foi extinto.

${ }^{4}$ Essa matéria foi publicada no boletim Contato. O site www.servidor.gov.br no qual o boletim Contato estava disponível foi extinto.
} 
política que contemplasse as ações de saúde e segurança, incluindo tratamento, prevenção e condições de trabalho, prevendo procedimentos padronizados para todos os órgãos da APF ${ }^{5}$.

Em 2006, houve a instituição do Sistema Integrado de Saúde Ocupacional do Servidor Público Federal (Sisosp), através do Decreto no 5.961, de 13 de novembro de 2006, e a publicação do Manual para os Serviços de Saúde dos Servidores Civis Federais $^{6}$. Esse manual englobava todos os procedimentos a serem seguidos pelos departamentos médicos em relação aos afastamentos para tratamento de saúde dos servidores e, teoricamente, organizava os procedimentos voltados aos cuidados à saúde do servidor público.

Entretanto, nem todos os órgãos mantinham departamento médico em sua estrutura e, apesar da formação técnica, os servidores que fariam parte da composição de novas equipes de trabalho, previstas pelo Sisosp, estavam alocados em outras funções, além de não estarem preparados para exercer as atividades propostas. Novamente, cada órgão tentou se adaptar às orientações dentro das suas possibilidades administrativas, criando diferentes formas de cumprir os novos procedimentos (CARNEIRO, 2011).

Em continuidade à construção e ao aprimoramento das orientações, foram realizados, a partir de 2007, encontros, oficinas e reuniões, envolvendo sempre o MPOG, servidores públicos federais das áreas da saúde e de recursos humanos e entidades sindicais (CARNEIRO, 2011).

Em decorrência dessas discussões, em 2009, foi instituído o SIASS, por meio da PASS ${ }^{7}$, conforme o Decreto no 6.833, de 29 de abril de 2009 (BRASIL, 2009a):

[...] Art. 2o O SIASS tem por objetivo coordenar e integrar ações e programas nas áreas de assistência à saúde, perícia oficial, promoção, prevenção e acompanhamento da saúde dos servidores da administração federal direta, autárquica e fundacional, de acordo com a política de atenção à saúde e segurança do trabalho do servidor público federal, estabelecida pelo Governo.

Em documento explicativo divulgado no sítio eletrônico do SIASS, encontramos mais detalhadamente as pretensões da PASS:

\footnotetext{
${ }^{5}$ Essa matéria foi publicada no boletim Contato. O site www.servidor.gov.br no qual o boletim Contato estava disponível foi extinto.

${ }^{6}$ Essa matéria foi publicada no boletim Contato. O site www.servidor.gov.br no qual o boletim Contato estava disponível foi extinto.

${ }^{7}$ Assim como o Comitê Gestor de Atenção à Saúde do Servidor, no âmbito do Ministério do Planejamento, Orçamento e Gestão, no artigo 4ํ do mesmo decreto.
} 
[...] consolidar práticas que surjam de uma concepção biopsicossocial do processo saúde e doença no trabalho, com um referencial de saúde direcionado à integralidade do ser humano, fundamentadas na gestão de dados epidemiológicos, na organização e intervenção nos ambientes de trabalho e no investimento em formação de equipes multiprofissionais para abordagem dos problemas (BRASIL, 2010b, paginação irregular).

\section{O papel do SIASS no seio da PASS}

As unidades do SIASS têm por finalidade articular os recursos existentes e propor medidas para a implementação das ações da PASS, sustentada a partir dos eixos vigilância e promoção à saúde, assistência à saúde do servidor e perícia em saúde (BRASIL, 2010b).

Essas unidades são sediadas por órgãos da APF que, pela natureza das suas atividades, detêm experiência, conhecimento e força de trabalho para promover as ações da PASS, de modo a atender os servidores das instituições partícipes por meio de um acordo de cooperação técnica firmado, conforme previsto na Portaria no 1.397, de 10 de agosto de 2012 (BRASIL, 2012) ${ }^{8}$.

Nesse contexto, assim como as unidades do SIASS, as áreas de RH são os principais agentes na implantação dessa política. Conforme previsto, as instituições públicas ficam obrigadas não só a cumprirem as orientações, mas também a promoverem a realização de ações de prevenção, promoção e qualidade de vida nos seus locais de trabalho (BRASIL, 2010b).

A previsão legal do trabalho de intermediação com a unidade do SIASS realizado pelos servidores da área de RH consta na Portaria $\mathrm{n}$ ㅇ 1.397, de 10 de agosto de 2012 (BRASIL, 2012), entre os incisos do artigo 10, que dita as competências de órgãos e entidades:

Art. 10. Compete aos órgãos e entidades partícipes do acordo de cooperação técnica, conjuntamente, na forma descrita no artigo 4을 desta Portaria: [...]

IX - encaminhar os casos necessários para avaliação na unidade do SIASS; [...] (BRASIL, 2012).

Os principais atores para efetivação da PASS estão definidos no artigo 6o da Portaria Normativa no 3, de 07 de maio de 2010. São eles: CGASS, Departamento de Saúde, Previdência e Benefícios do Servidor (Desap/SRH/MP), dirigente do

\footnotetext{
${ }^{8}$ As unidades do SIASS espalhadas pelo País podem ser identificadas no seguinte sítio eletrônico: https:// www2.siapenet.gov.br/saude/portal/public/index.xhtml. A maioria delas tem sido sediada pelo INSS e pelas universidades federais.
} 
órgão ou entidade, gestor de pessoas ou de RH, Equipe de Vigilância e Promoção da Saúde, Comissão Interna de Saúde do Servidor Público (CISSP) e servidores em geral (BRASIL, 2010c).

\section{Ações previstas na PASS}

Entre as principais normativas que orientam os órgãos na realização dessas ações, temos aquelas referentes às licenças médicas (BRASIL, 2009c), aos exames médicos periódicos (BRASIL, 2009b), à vigilância dos ambientes de trabalho (BRASIL, 2013a) e às ações de prevenção e promoção à saúde (BRASIL, 2013b).

Os controles relacionados a tais normativas devem ser registrados em sistema informatizado integrado ao MPOG, chamado de Siape-Saúde ${ }^{9}$, de forma a manter os registros das ações de saúde praticadas pelas instituições e pelo SIASS. Atualmente, os módulos em funcionamento são aqueles para os registros das ações de promoção à saúde, dos exames periódicos e dos afastamentos para tratamento de saúde dos servidores (atestados e perícias).

Dentre as práticas previstas nessas normativas, destacamos a composição das equipes multidisciplinares nas unidades do SIASS que servem para subsidiar a perícia em saúde (BRASIL, 2010c). Essa prática está prevista na Norma Operacional de Saúde do Servidor Público Federal (NOSS); nos Princípios, Diretrizes e Ações em Saúde Mental; e nas Diretrizes Gerais de Promoção da Saúde - Portaria Normativa SRH no 3, de 07 de maio de 2010 (BRASIL, 2010d); Portaria SRH no 1.261, de 05 de maio de 2010 (BRASIL, 2010b); e Portaria Normativa no 3, de 25 de março de 2013 (BRASIL, 2013b), respectivamente.

Esses documentos também preveem que as ações e as práticas da PASS devem estar em consonância com as políticas públicas de saúde do trabalhador, fundamentadas nos "princípios humanitários e éticos de igualdade, equidade e não discriminação, do direito à privacidade e à autonomia individual, da abolição do tratamento desumano e degradante, garantindo o tratamento adequado", conforme previsto inciso II, do artigo 1ํㅡ, da Portaria SRH no 1.261, de 05 de maio de 2010 (BRASIL, 2010d).

${ }^{9}$ Siape: Sistema Integrado de Administração de Recursos Humanos. 
Em relação à promoção e vigilância da saúde, dois importantes materiais estão disponibilizados em meio eletrônico:

- Promoção e vigilância em saúde: guia para as ações no setor público federal (Assunção, 2012); e

- Políticas públicas de saúde: servidor público federal (DIAS et al., 2014).

Entre as ações previstas, a perícia em saúde é a que está melhor formalizada, realizada pelas unidades do SIASS, cuja finalidade é:

[...] uniformização de procedimentos, transparência dos critérios técnicos, eficiência administrativa, humanização no atendimento, racionalidade de recursos, bem como ao apoio multidisciplinar e às relações com as áreas da assistência e da promoção à saúde (BRASIL, 2010d, paginação irregular).

O Manual de Perícia Oficial em Saúde do Servidor Público Federal (BRASIL, 2010a) esclarece aos peritos e às áreas de $\mathrm{RH}$ sobre os procedimentos e as exigências das legislações para a realização desse trabalho, constantes na Lei no 8.112, de 11 de novembro de 1990 (BRASIL, 1991).

Em geral, todos os controles e os registros referentes aos afastamentos por motivo de saúde que não necessitam de perícia ou junta médica, as informações para realização dos exames médicos periódicos e as descrições dos programas de promoção da saúde realizados têm sido inseridos no sistema Siape-Saúde pelas respectivas áreas de $\mathrm{RH}$, que se responsabilizam também pelas atividades de encaminhamento, apoio e intermediação para o desenvolvimento das ações em saúde dentro das instituições.

\section{Os agentes de RH no trabalho de intermediação}

Os agentes de $\mathrm{RH}$ entrevistados possuem idade entre 43 e 60 anos, a maioria com mais de 29 anos de trabalho no serviço público federal e experiência na área de RH que varia entre 2 a 35 anos. A maioria possui curso de nível superior completo. Três dos agentes possuem também curso de especialização lato sensu, mas nenhum dos agentes participou de programas ou eventos de capacitação relacionados à temática de saúde e trabalho no serviço público.

Dos 10 agentes entrevistados, identificamos que um não trabalha na área de RH, dois trabalham no setor relacionado a benefícios e assistência médica, vinculados institucionalmente à área administrativa, mas não ao RH.

Os servidores abrangidos pelo trabalho dos agentes de $\mathrm{RH}$ são aqueles que trabalham no Estado de São Paulo, porém alguns agentes intermediam a perícia para servidores de outros estados quando esses estão de passagem ou em 
tratamento médico na cidade de São Paulo. Apenas dois órgãos atendem somente os servidores da cidade de São Paulo.

Em relação às orientações prescritas para a realização do trabalho de intermediação, os agentes se baseiam no Regime Jurídico Único (RJU) dos Servidores Públicos Federais - Lei no 8.112/1990 (BRASIL, 1991) - e nas normativas e orientações específicas que tratam dos procedimentos para as licenças por motivo de saúde. Dois dos agentes disseram utilizar também o Manual de Perícia (BRASIL, 2010a) ${ }^{10}$, material distribuído pelo SIASS, em que constam todos os procedimentos e os motivos que levam o encaminhamento do servidor para avaliação da perícia médica.

As atividades de intermediação entre o servidor e a unidade do SIASS para realização da perícia médica, incluindo o acompanhamento dos afastamentos e os controles que demanda esse trabalho, não são as únicas realizadas pelos agentes de $\mathrm{RH}$. Eles realizam diversas atividades operacionais sem relação com os assuntos voltados à saúde do servidor.

Antes da criação do SIASS, alguns órgãos mantinham internamente um departamento médico composto por servidores com formação na área da saúde, no qual eram realizadas as perícias e as juntas médicas. Dois dos agentes disseram ter trabalhado nesse departamento, realizando a intermediação e, no total, seis disseram ter realizado a intermediação entre o servidor e a perícia médica antes da criação do SIASS.

\section{Os agentes de RH na ação de intermediação: impedimentos e possibilidades}

\section{Contexto de trabalho dos agentes de $\mathrm{RH}$}

A maioria dos agentes de RH entrevistados faz parte de órgãos públicos federais cujas sedes estão localizadas em Brasília-DF. Cada um dos órgãos em São Paulo possui uma área de $\mathrm{RH}$ regional que presta suporte ao $\mathrm{RH}$ central.

Os agentes de RH também intermediam o encaminhamento de informações e documentos necessários para constarem no prontuário do servidor e/ou serem inseridos no sistema de folha de pagamento - Siape ${ }^{11}$. Dessa atividade desdobramse os demais controles realizados em planilhas e sistemas, além do trabalho de intermediação com o SIASS, do atendimento aos servidores e demais demandas mensais da área.

\footnotetext{
${ }^{10}$ As informações contidas nesse manual são estritamente teóricas, voltadas ao esclarecimento dos peritos.

${ }^{11}$ Siape: Sistema Integrado de Administração de Recursos Humanos.
} 
Os agentes demonstraram preocupação quanto à quantidade de tarefas que estão sob sua responsabilidade: "[...] porque é muita demanda [...]. Eu me perco no meio. Às vezes eu chego ao trabalho e falo: 'gente não sei por onde eu começo'" (A2).

Entre todos, chamou-nos atenção o caso de um dos agentes que acompanha todo o processo de realização dos exames médicos periódicos de 930 servidores da instituição. $O$ excesso de trabalho é agravado pela falta de pessoal e a iminente aposentadoria dos agentes.

Há dificuldade de usufruir férias ou de se ausentar por não ter quem realize o trabalho:

Férias!? Eu não posso tirar férias de 30 dias. Esse ano mesmo eu interrompi minhas férias. [...] Do dia 10 ao dia 7, voltei exclusivamente para fazer o fechamento da folha (A3).

A realização do concurso público, como alternativa para solucionar o excesso de trabalho e a descontinuidade das atividades, é colocada como improvável:

Hoje, todo o serviço público está com seus recursos humanos reduzidíssimos. E isso acarreta uma sobrecarga de trabalho, eu acho que pela falta de concurso, principalmente na área de nível médio para atendimento das atividades da área meio (A7).

Em relação à realização de programas e ações institucionais voltados à saúde do servidor, verificamos sua ocorrência em apenas uma das instituições, onde o próprio agente de RH é quem coordena as atividades. Em outros dois órgãos, há ações pontuais com participação dos agentes, mas enfraquecidas, com suas periodicidades prejudicadas.

\section{O papel dos agentes de RH no trabalho de intermediação}

O trabalho de intermediação é realizado de forma variada entre as instituições. Na maioria, o servidor ou o familiar entrega o atestado pessoalmente, sendo esse primeiro contato estabelecido para que os demais ocorram por telefone e/ou e-mail: "Então é assim: o servidor, quando ele pode, ele vem e traz o atestado. Senão vem um familiar ou ele manda para o meu e-mail" (A1).

“O procedimento é: se a pessoa está em tratamento de saúde ou tem qualquer documento referente à saúde dela ou do familiar, ela deve buscar [o setor de RH] pra receber as informações e ter os encaminhamentos" (A4).

Há também a intermediação com a unidade regional do órgão ou diretamente com uma agência do Instituto Nacional do Seguro Social (INSS) da localidade onde trabalha o servidor, no intuito de conseguir a realização da perícia e a homologação 
do afastamento quando não há unidade do SIASS nas proximidades. Os agentes relataram a dificuldade de conseguir a disponibilidade de atendimento do INSS e do próprio servidor para ir à perícia. Em uma das instituições houve intervenção do sindicato, que orientou os servidores quanto ao direito de realizar perícia médica somente no município de lotação.

Uma das principais preocupações dos agentes de RH é a homologação dos afastamentos para que o servidor não tenha prejuízos salariais. Por esse motivo, empenham-se em conseguir o atestado médico, o agendamento e a ida do servidor à perícia: "Então, dependendo do familiar, você tem que estar ligando: 'olha, venceu, corre atrás, vai atrás de seu médico, pega outro atestado, você tem que trazer isso aqui, não esquece"” (A4).

A essa preocupação, acrescenta-se o empenho no cumprimento das normativas que regem o trabalho de intermediação e os controles institucionais, com destaque para os prazos e o atendimento do padrão exigido para os atestados médicos que serão avaliados pela perícia, ou seja, que estejam legíveis, com nome, período do afastamento, Código da Classificação Internacional de Doenças (CID) etc.

Por outro lado, os agentes relataram a falta de conhecimento e interesse por parte dos servidores em relação às exigências legais e aos procedimentos a serem seguidos para formalização dos afastamentos por motivo de saúde. Além disso, convivem com os esquecimentos ou compromissos de trabalho que impedem a ida dos servidores à perícia: "Aqui [na instituição] a gente tem um problema: [...] Nós agendamos e aí: 'ah, tive uma convocação não sei pra onde, não fui!'” (A2).

Na realização do trabalho de intermediação, os agentes passam a conhecer os problemas de saúde dos servidores. A maioria dos agentes demonstrou preocupação com os servidores acometidos por problemas psiquiátricos (CID F):

Reação aguda ao estresse. Os 'Fs da vida'... O maior índice é esse (A2).

[...] a gente procura acompanhar esses casos graves, né? [...] O que mais nos preocupa é quando vêm os Fs... A gente faz um acompanhamento mais de perto, entende? Porque é preocupante (A3).

Durante as entrevistas, também surgiram casos relacionados a outros problemas de saúde, com destaque para os oncológicos, os ortopédicos, aqueles relacionados às LER/DORT e à dependência química:

[...] psiquiátrico e de câncer. Às vezes coluna" (A5).

[...] servidor que ficou um ano fazendo o mesmo tratamento, problema que afetou o ombro, pescoço, seria a LER. Agora ele voltou e está usando uma cadeira especial [...] (A10). 
Alguns agentes relataram peculiaridades das atividades exercidas pelos servidores, evidenciando a percepção da relação entre os adoecimentos e o trabalho desempenhado:

Às vezes a pessoa não quer ir viajar. [...] Quando chega lá, o serviço é complicado, é difícil, muitas vezes chega a ser perigoso, tudo isso gera uma tensão (A1).

Certeza. Não todos, mas a maioria sim, por estresse, tensão no trabalho, cobrança. [...] Tem dia que o sistema não funciona, o telefone não funciona, tem muito trabalho, pouco funcionário, o que gera estresse e doença (A9).

Em alguns casos de afastamentos por motivos psiquiátricos, os agentes relataram dificuldades do servidor em ir a consultas médicas e, posteriormente, levar o atestado até a instituição. Nos casos que geram afastamentos com períodos mais longos, é realizado um acompanhamento, mesmo distanciado, em relação aos cuidados de saúde realizados pelo servidor, do retorno ou não ao trabalho e, algumas vezes, contato telefônico com os familiares, pelo qual orientam quanto à necessidade de realização da perícia médica.

Em relação ao retorno ao trabalho, quando do término do afastamento médico do servidor, os agentes de RH disseram acatar a orientação discriminada no laudo pericial de retornar ou não à perícia na unidade do SIASS. As instituições não possuem práticas de readaptação. Nos casos em que o servidor apresentou recomendações médicas, a situação foi levada à chefia imediata para que os cuidados necessários fossem seguidos: "A própria chefia acompanha. Se o nosso RH percebe que não está cumprindo aquilo, lembramos a chefia:'olha, ele está se readaptando'" (A7).

A importância da ética no trabalho de intermediação foi ressaltada pelos agentes em relação à preocupação com o sigilo das informações pessoais do servidor que passam pelo seu conhecimento:

[...] o fato de não ter um profissional qualificado pra atender o servidor num certo momento não quer dizer que eu tenho o direito de expor a vida dele, de contar ou repassar aquilo que ele vem me dizer. Ouço histórias mil, sei de coisas da vida dessas pessoas, mas eu não tenho o direito de dizer isso nunca a ninguém. Não posso (A4).

Ao serem perguntados sobre qual seria o papel do agente de $\mathrm{RH}$ no trabalho de intermediação, todos responderam que é o de receber o atestado médico, agendar e encaminhar o servidor para realização da perícia, mas, cada um ao seu modo, complementou a resposta explicando que o trabalho vai além, pois, ao atender o servidor com problemas de saúde, é levado a desempenhar outros papéis: 
Entendo que não é uma coisa mecânica, pegar o papel, mandar pro SIASS (A1).

É um facilitador. Vê qual o melhor momento que ele pode vir. De repente ele não tem condições de vir numa perícia naquele momento, intermediar um prazo mais longo até ele ter condições (A2).

Então, eu acho que o papel é esse, seria só receber a documentação e dar uma informação. Mas não é só isso que você pode fazer. Você tem que fazer mais nesse momento de vida do funcionário (A4).

Apesar dessa percepção, a atenção despendida no atendimento aos servidores - o envolvimento com a história de vida, da saúde, o interesse, a escuta, a disponibilidade para o diálogo - varia entre os agentes, sendo maior ou menor dependendo do agente. Alguns acompanham os casos, demonstram disposição e abertura para ouvir. No entanto, uma maior amplitude dessa atividade é impedida pela ausência de condições e por prescrições possíveis à realidade de trabalho dos agentes:

E você tem que ouvir histórias e você não poder fazer nada, porque você não tem nem pra onde encaminhar esse servidor. Então você fica de mãos atadas [...] (A4).

Outros tentam manter a impessoalidade, fazer o que deve ser feito em relação aos controles e ao cumprimento das normativas...

\section{A unidade do SIASS como ação estratégica da PASS}

A equipe da unidade do SIASS, mencionada durante as entrevistas pelos agentes, é composta por servidores que cuidam do atendimento e dos trabalhos administrativos, um coordenador, vários médicos peritos e um psicólogo.

O atendimento prestado por esses profissionais, tanto para os agentes no trabalho de intermediação, quanto para os servidores avaliados pela perícia, foi elogiado por todos. Os funcionários estão sempre prontos a remediar os entraves operacionais, procurando despender atenção nas pequenas soluções do dia a dia. A simpatia também foi citada em relação a esse atendimento, todavia, houve queixas em relação à morosidade no retorno dos agendamentos, das documentações e dos laudos emitidos após avaliação da perícia.

No que tange a treinamentos, os agentes disseram ter participado de um organizado pela equipe administrativa da unidade sobre as regras das licenças por motivos de saúde dos servidores consideradas de curta duração. Teve como objetivo ensinar os procedimentos para lançamento dos respectivos atestados médicos no sistema Siape-Saúde. Quase todos os agentes participaram desse treinamento, o único ofertado pela unidade até o momento. 
Em relação à avaliação pericial, os agentes não compreendem que o trabalho dos peritos contribui para a saúde dos servidores. Um deles complementou que a demora no agendamento prejudica o trabalho da perícia, pois o servidor, quando passa pela avaliação, já está curado da enfermidade: “Quando a pessoa vai fazer a perícia, ela não tem mais nada pra mostrar. [...] Só homologou o atestado. O papel deles é homologar o atestado, não é a perícia" (A9).

Apesar da confirmação de que os lançamentos no sistema Siape-Saúde têm sido realizados, os históricos dos afastamentos médicos dos servidores continuam sendo encaminhados aos peritos, o que nos permite levantar a hipótese de que as informações epidemiológicas constantes no sistema não têm sido utilizadas.

Em relação aos casos de adoecimentos mais relevantes, as orientações prestadas pela unidade do SIASS aos agentes de RH são pontuais, não se estendem ao foco do problema. Geralmente são os próprios agentes que procuram orientações, movidos pela situação de saúde do servidor.

A indefinição quanto às ações de assistência ao servidor é motivo de preocupação entre os agentes:

E você tem que ouvir histórias e você não poder fazer nada, porque você não tem nem pra onde encaminhar esse servidor. Então você fica de mãos atadas [...] (A4).

Também não foram mencionadas pelos agentes ações de prevenção e/ou promoção à saúde, incentivadas ou realizadas pela unidade do SIASS. Um dos agentes de $\mathrm{RH}$ que presta apoio nas atividades administrativas da unidade - como forma de contribuição da instituição prevista no Acordo de Cooperação Técnica confirmou tal situação, havendo a expectativa de conseguir formar uma equipe multiprofissional para avançar nas ações propostas ao SIASS.

\section{Discussão}

Por meio deste estudo, verificamos que o papel dos agentes de $\mathrm{RH}$ no trabalho de intermediação entre os servidores e a unidade do SIASS tem sido desempenhado, sobretudo, nas práticas de controle dos afastamentos. Essa realidade ocorre diante da indefinição desse papel e pela insuficiência dos meios e dos recursos que impedem ações mais efetivas em prevenção, promoção e assistência à saúde dos servidores, propostas pela PASS.

Em relação aos meios disponíveis, verificamos a ausência de orientações internas que definam como realizar o trabalho de intermediação. Os agentes têm 
se baseado nas normativas prescritas pela política e em orientações da unidade do SIASS prestadas individualmente a partir dos questionamentos dos agentes.

Outra deficiência é o quadro reduzido de servidores nas instituições, agravado pela proximidade das aposentadorias dos agentes. O concurso público como solução para essa problemática não parece ser uma possibilidade imediata. Os agentes têm dificuldade de se ausentar do trabalho, seja para usufruir das férias ou por qualquer outro motivo, pois não têm com quem dividir as tarefas. Eles organizam as ausências em função dos prazos em que o trabalho precisa ser realizado. Esse cenário foi descrito pelos agentes com desânimo, pois trabalham com a perspectiva da descontinuidade, ou seja, suas experiências não serão transmitidas e tudo aquilo que foi desenvolvido e aprimorado por eles corre o risco de acabar.

Cadastro desatualizado, problemas no recebimento de e-mails trocados entre a instituição e a unidade do SIASS, falta de espaço para atendimento e fragilidade das ações institucionais voltadas à saúde dos servidores são outras impossibilidades que se colocam para o trabalho. Essas deficiências institucionais possuem características conhecidas como próprias do serviço público (NUNES; LINS, 2009; RIBEIRO; MANCEBO, 2013) e geram a ocorrência de agravos à saúde dos trabalhadores, devido aos constantes impedimentos na realização das ações propostas, que reduzem a margem de ação nas situações de trabalho (VILELA; SILVA; JACKSON FILHO, 2010). Prevalecem as atividades voltadas ao controle, sem indícios de aperfeiçoamento dos mecanismos existentes, ao contrário do proposto pelos princípios da administração, que buscam alcançar a modernização do Estado (AZEVEDO; LOUREIRO, 2003).

Nesse contexto, os agentes se dedicam cada vez mais ao trabalho burocrático ditado pelas práticas gerenciais - buscam alcançar eficiência por meio da realização das tarefas. Pela ausência de procedimentos padronizados, identificamos diversas práticas para realizar o mesmo trabalho, acrescentando-se a duplicidade no armazenamento das informações em planilhas, sistemas e prontuários ao excesso de atividades operacionais e às responsabilidades acumuladas. $\mathrm{O}$ dever do controle soma-se à atividade de atender o servidor com problemas de saúde, reduzindo a intermediação à perícia médica, sem alcance do proposto pela PASS.

Cientes de seu contexto de trabalho, mas sensibilizados com os problemas de saúde dos servidores, os agentes procuram ter iniciativas que amenizem a situação, como o empenho em regularizar o afastamento, evitando ou revertendo perdas salariais, em reagendar ou conseguir determinada data de agendamento da perícia, em buscar orientações na unidade do SIASS e, em alguns casos, até realizar o acompanhamento e a escuta dos servidores atendidos. Nesse sentido, podemos inferir que a dedicação dos agentes poderia ser expandida para além do controle 
dos afastamentos, tendo em vista que eles demonstram preocupação e interesse no acompanhamento dos servidores em licença por motivos de saúde.

Não há definição, todavia, sobre como a assistência deve ser prestada pelos agentes de $\mathrm{RH}$, prevalecendo o papel do controle, imposto indiretamente por meio das normativas, do excesso de trabalho e do único treinamento recebido, ministrado pela unidade do SIASS, relativo ao lançamento de atestados no sistema SiapeSaúde. O trabalho se coloca cada vez mais abstrato e distante da realidade (LHUILIER, 2011) dos adoecimentos nas instituições. As tarefas voltadas aos regramentos têm sido cumpridas, alcançadas, exercidas exaustivamente pelos agentes, que ficam impossibilitados de desenvolver suas potencialidades.

Além dos problemas estruturais vivenciados pelos agentes, sabe-se que é característica das áreas de RH o convívio com as contradições que se colocam entre o compromisso firmado com as pessoas às quais atendem e o cumprimento do trabalho (LACOMBE; BENDASSOLLI, 2004). Diante do cenário de trabalho, os agentes de $\mathrm{RH}$ despendem esforços e iniciativas que supram as insuficiências, buscam alternativas para prestar a mínima assistência ao servidor atendido, mesmo com a ausência de autonomia e condições para realizar o trabalho.

Tais fatos vão ao encontro do que diz Clot (2010), pois ao realizar a atividade, o indivíduo vai além do prescrito, desenvolve seu poder de agir, dando sentido e eficiência à ação, conforme as possibilidades e/ou impossibilidades que se apresentam. Isso não descarta a necessidade de se definir como a assistência deve ser prestada, quais são os limites de ação dos agentes de RH diante das situações de adoecimentos.

A unidade do SIASS colocada pela PASS como recurso para ação parece sofrer dos mesmos problemas estruturais enfrentados pelos agentes de RH nas instituições. Essa conclusão se baseia nas queixas apresentadas pelos agentes, que evidenciam que a unidade do SIASS não tem cumprido a finalidade para qual foi criada. Realidade semelhante foi descrita por Zanin et al. (2015) sobre a unidade SIASS-UFPR ${ }^{12}$.

As instituições atendidas pela unidade do SIASS possuem missões diferenciadas, sendo possível observar, por meio dos relatos dos agentes, que, em alguns casos, o trabalho exercido pelos servidores parece acarretar adoecimentos. Assim, desempenhar ações somente na perícia médica, focada na homologação dos afastamentos, é deixar de lado as peculiaridades de cada tipo de trabalho e as questões de saúde que se manifestam nas instituições.

\footnotetext{
12 Outra crítica se volta ao caráter transversal do subsistema, que não está atrelado diretamente a nenhuma instituição ou ministério, portanto não dispõe de orçamento próprio, nem força política. Com relação às instituições que atende, pode-se supor que não tem poder suficiente para possíveis enfrentamentos em casos de litígio com a direção das mesmas.
} 
As impossibilidades que se colocam no trabalho de intermediação fazem com que os agentes trabalhem na realização daquilo que é possível. O papel a ser desempenhado além do controle passa a ser questão pessoal, desamparado em sua essência pela instituição, pela unidade do SIASS e, principalmente, pela PASS. Podemos dizer que o trabalho de intermediação se realiza porque os agentes de RH "mobilizam sua inteligência prática para fazer as coisas acontecerem a despeito das regras e dos procedimentos prescritos frequentemente inaplicáveis [...]" (CHANLAT, 2011, p. 117).

Sznelwar, Mascia e Bouyer (2006) explicam ainda que os trabalhadores possuem diversas possibilidades de agir na realização do seu trabalho, mesmo diante das regras. Concentram sua atenção nas atividades fazendo uso da sua vontade e do seu livre arbítrio. Porém, em certos sistemas, o uso estrito de prescrições e regras, impostas pela gestão, pode impedir a realização das atividades, limitando a margem de ação e, consequentemente, o próprio funcionamento da organização (SZNELWAR; MASCIA; BOUYER, 2006; VILELA; SILVA; JACKSON FILHO, 2010).

No caso dos agentes de RH, a margem de ação que se coloca é a operacionalização de atividades que tendem a reduzir a política ao controle, ao mesmo tempo em que vivenciam as deficiências do meio, as insuficiências da unidade do SIASS, a fragilidade da saúde dos servidores afastados, as dificuldades de fazer cumprir a realização da perícia, os diversos procedimentos operacionais e as exigências institucionais. O cenário é de ausência de possibilidade para a realização de ações de saúde mais efetivas, deixando-os cada vez mais distantes do verdadeiro potencial de contribuição de seu trabalho.

As experiências no trabalho de intermediação fazem dos agentes de $\mathrm{RH}$ atores importantes na implementação da PASS. Eles acompanham, ainda que baseados no controle dos afastamentos, o histórico dos adoecimentos dos servidores, acumulando informações que poderiam contribuir para o avanço das ações em saúde e trabalho no serviço público federal.

Além disso, o "desenho estratégico das políticas deve incluir a identificação dos atores que dão sustentação à política e mecanismos de concertação e negociação entre tais atores" (SILVA; MELO, 2000, p. 13). Portanto, o papel dos agentes de RH é algo a ser definido pela PASS, o que ultrapassaria a responsabilidade indireta delegada a eles pelos órgãos e entidades.

A capacitação dos agentes em saúde e trabalho com enfoque no serviço público favorece uma atuação mais expressiva em relação à PASS, pois o aprendizado e a discussão ampliam o espaço para contribuições desses agentes, tanto no trabalho cotidiano da intermediação, quanto em relação às ações da política. A continuidade 
dos eventos propostos pelo MP (CARNEIRO, 2011) é, portanto, fundamental para a efetividade das ações.

Souza e Reis (2013) compreendem que uma das demandas necessárias em saúde do trabalhador é a realização de discussões no espaço de trabalho como meio de reconhecimento dos adoecimentos e de ampliação da compreensão sobre políticas em saúde do trabalhador:

Entendemos que a participação dos servidores públicos no processo de ampliação das políticas de saúde do trabalhador é fundamental, pois são eles que vivenciam as experiências e podem dizer o que sentem e o que os afeta (SOUZA; REIS, 2013, p. 102).

Por outro aspecto, alguns autores também defendem a criação de um espaço em que o coletivo possa fazer uso da palavra para verbalizar e discutir o trabalho (DEjours, 1993; ChANLAT, 1993), por meio do que é possível não só identificar problemas, organizar e definir responsabilidades, mas também mobilizar qualidades individuais e proporcionar alto potencial preventivo à saúde e à segurança no trabalho (DEJOURS,1993).

Desse modo, considerando as contribuições do coletivo para o trabalho, a formação de um grupo permanente composto pelos agentes de RH que fazem parte do mesmo Acordo de Cooperação Técnica com a unidade do SIASS deveria ser viabilizada. A integração entre eles poderia ocorrer por meio de reuniões periódicas para dialogar sobre o trabalho: discutir as práticas, os procedimentos prescritos, a política, trocar experiências, expor e encaminhar os problemas e encontrar soluções que, talvez, já poderiam ter sido executadas, mas, pelo distanciamento entre as instituições e os agentes, ainda não foram adotadas.

Para além dessa ação, por que não constituir uma rede ou comunidade (MASSARDIER, 2006) composta pelos agentes de RH do País que pudesse, mais do que trocar informações e experiências, produzir compromissos de trabalho em relação a objetivos comuns que tragam contribuições para a construção da política?

Ressaltamos que a interlocução entre as instituições é prevista tanto no Decreto no 6.833, de 29 de abril de 2009 (BRASIL, 2009a), que trata da criação das unidades do SIASS, como na Portaria no 1.397, de 10 de agosto de 2012 (BRASIL, 2012), que orienta acerca da formalização dos acordos.

\section{Conclusões}

Este estudo possibilitou identificar que o papel dos agentes de $\mathrm{RH}$ tem se pautado, sobretudo, nas práticas de controle dos afastamentos dos servidores ao trabalho, 
orientadas pelas prescrições possíveis diante das deficiências estruturais das instituições e pela ausência de definição de seu papel no trabalho de intermediação realizado entre os servidores e a unidade do SIASS da cidade de São Paulo. Fazse necessário ampliar a margem de ação dos agentes de $\mathrm{RH}$ através da melhoria dos meios e dos recursos, assim como da manutenção de processo contínuo de capacitação voltado à temática de saúde e trabalho com ênfase no serviço público.

Por fim, embora o caminho metodológico desta pesquisa tenha permitido apenas compreender a realidade de trabalho dos agentes de $\mathrm{RH}$, pode-se observar, por meio dela, seu papel fundamental na implementação da política, que, malgrado suas insuficiências institucionais, ainda se pode constituir como oportunidade para sanar a falta histórica do olhar do Estado brasileiro para a saúde dos trabalhadores públicos (RAMMINGER; NARDI, 2007).

\section{Referências}

ABRUCIO, F. L. Trajetória recente da gestão pública brasileira: um balanço crítico e a renovação da agenda de reformas. Revista de Administração Pública (RAP), Rio de Janeiro, Edição Especial Comemorativa: 1967-2007, p. 67-86, 2007.

ANDRADE, E. T. O processo de implementação da política de atenção à saúde do trabalhador em instituições públicas federais: o desafio da integralidade. Rio de Janeiro: Fiocruz, 2009. 128 f. Dissertação (Mestrado em Ciências) - Escola Nacional de Saúde Pública/Fundação Oswaldo Cruz, Rio de Janeiro. Disponível em: <http:// www.arca.fiocruz.br/bitstream/icict/2522/1/ENSP_Disserta\%c3\%a7\%c3\%a3o_ Andrade_Elsa_Tom\%c3\%a9.pdf>. Acesso em: 27 nov. 2012.

Assunção, A. A. (Org.). Promoção e vigilância em saúde: guia para as ações no setor público federal. Belo Horizonte: [s.n.], 2012. Disponível em: <http://pt.scribd.com/ doc/118956027/Promocao-e-Vigilancia-Em-Saude>. Acesso em: 10 set. 2014.

Azevedo, C. B.; Loureiro, M. R. Carreiras públicas em uma ordem democrática: entre os modelos burocrático e gerencial. Revista do Serviço Público, Brasília, ano 54, v. 1, n. 1, p. 47-61, jan./mar. 2003.

BARDIN, L. Análise de conteúdo. São Paulo: Edições 70, 2011.

BRASIL. Lei no 8.112, de 11 de dezembro de 1990. Dispõe sobre o regime jurídico dos servidores públicos civis da União, das autarquias e das fundações públicas federais. Diário Oficial [da] República Federativa do Brasil, Brasília, DF, 19 abril 1991. Disponível em: <http://www.planalto.gov.br/ccivil_03/leis//8112cons.htm>. Acesso em: 15 out. 2012.

BRASIL. Decreto no 6.833, de 29 de abril de 2009. Institui o Subsistema Integrado de Atenção à Saúde do Servidor Público Federal - SIASS e o Comitê Gestor de Atenção à Saúde do Servidor. Diário Oficial [da] República Federativa do Brasil, Brasília, DF, 30 abril 2009a. Seção 1, p. 4.

BrASIL. Presidência da República. Casa Civil. Decreto no 6.856, de 25 de maio de 2009. Diário Oficial [da] República Federativa do Brasil, Brasília, DF, 26 maio 2009b. 
Disponível em: <http://www.planalto.gov.br/ccivil_03/_ato2007-2010/2009/ decreto/d6856.htm>. Acesso em: 07 jan. 2014.

BRASIL. Presidência da República. Casa Civil. Decreto no 7.003, de 09 de novembro de 2009. Diário Oficial [da] República Federativa do Brasil, Brasília, DF, 10 nov. 2009c. Disponível em: <http://www.planalto.gov.br/ccivil_03/_Ato2007-2010/2009/ Decreto/D7003.htm>. Acesso em: 07 jan. 2014.

BRASIL. Ministério do Planejamento, Orçamento e Gestão. Secretaria de Recursos Humanos. Portaria no 797, de 22 de março de 2010. Institui o Manual de Perícia Oficial em Saúde do Servidor Público Federal. Diário Oficial [da] República Federativa do Brasil, Brasília, DF, 23 mar. 2010a. Seção 1, p. 53-54.

BRASIL. Ministério do Planejamento, Orçamento e Gestão. Secretaria de Recursos Humanos. SIASS - Subsistema Integrado de Atenção à Saúde do Servidor. Folder SIASS - PASS - NOSS - Saúde Mental - Saúde Suplementar - Base Legal. Brasília: MPOG, 2010b. Folder.

BRASIL. Ministério do Planejamento, Orçamento e Gestão. Secretaria de Recursos Humanos. Portaria Normativa no 3, de 7 de maio de 2010. Diário Oficial [da] República Federativa do Brasil, Brasília, DF, 10 maio 2010c. Disponível em: <http://pesquisa.in.gov.br/imprensa/jsp/visualiza/index. jsp?data $=10 / 05 / 2010$ \&jornal=1\&pagina $=80$ \&totalArquivos $=120>$. Acesso em: 20 dez. 2012.

BRASIL. Ministério do Planejamento, Orçamento e Gestão. Secretaria de Recursos Humanos. Portaria no 1.261, de 5 de maio de 2010. Diário Oficial [da] República FederativadoBrasil,Brasília,DF,06maio2010d.Disponívelem:<http://pesquisa.in.gov. br/imprensa/jsp/visualiza/index.jsp?jornal=1\&pagina=97\&data=06/05/2010>. Acesso em: 16 jul. 2013.

BRASIL. Ministério do Planejamento, Orçamento e Gestão. Secretaria de Recursos Humanos. Extrato de Acordo de Cooperação Técnica. Acordo de Cooperação Técnica no 20/2011, de 22/12/2011. Diário Oficial [da] República Federativa do Brasil, Brasília, DF, 23 dez 2011. Disponível em: <http://pesquisa.in.gov.br/imprensa/servlet/ iewer ?jornal=3\&pagina=333\&data=23/12/2011\& captchafield=firistAccess $>$. Acesso em: 23 ago. 2012.

BRASIL. Ministério do Planejamento, Orçamento e Gestão. Secretaria de Gestão Pública. Portaria no 1.397, de 10 de agosto de 2012. Estabelece orientações básicas para a realização de acordo de cooperação técnica. Diário Oficial [da] República Federativa do Brasil, Brasília, DF, 23 ago. 2012. Seção 1, p. 57.

BRASIL. Ministério do Planejamento, Orçamento e Gestão. Secretaria de Gestão Pública. Orientação Normativa no 6, de 18 de março de 2013. Diário Oficial [da] República Federativa do Brasil, Brasília, DF, 20 março $2013 a$. Disponível em: <http://pesquisa.in.gov.br/imprensa/jsp/visualiza/index. jsp?jornal=1\&pagina=75\&data=20/03/2013>. Acesso em: 20 jan. 2014.

BRASIL. Ministério do Planejamento, Orçamento e Gestão. Secretaria de Gestão Pública. Portaria Normativa no 3, de 25 de março de 2013. Diário Oficial [da] República Federativa do Brasil, Brasília, DF, 27 março 2013b. 
Disponível em: <http://pesquisa.in.gov.br/imprensa/jsp/visualiza/index. jsp?data=27/03/2013\&jornal=1\&pagina=77\&totalArquivos=112>. Acesso em: 20 jan. 2014.

CARneIRo, S. A. M. Saúde do trabalhador público: questão para gestão de pessoas a experiência na prefeitura de São Paulo. Revista do Serviço Público, Brasília, v. 1, n. 57, p. 23-49, jan./mar. 2006.

CARneiro, S. A. Saúde do trabalhador público: Uma questão para gestão de pessoas. In: Congresso ConSAd DE GestÃo PúbliCA, 4., 2011, Brasília. Anais... Brasília: Consad, 2011. Disponível em: <//repositório.fjp.mg.gov.br/consad/ handle/123456789/757>. Acesso em 19 ago. 2015.

CHANLAT, J. F. Por uma antropologia da condição humana nas organizações. In: O indivíduo na organização: dimensões esquecidas. 2. ed. São Paulo: Atlas,

1993. v. 1. p. 21-45.

Chanlat, J. F. O desafio social da gestão: a contribuição das ciências sociais. In: BendAsSOlLI, P. F.; SoBoll, L. A. (Orgs.). Clínicas do trabalho: novas perspectivas para compreensão do trabalho na atualidade. São Paulo: Atlas, 2011. p. 110-131.

CLOT, Y. Trabalho e poder de agir. Belo Horizonte: Fabrefactum, 2010.

COSTA, F. L. Condicionantes da reforma do Estado no Brasil. In: MARTINS, P. E. M.; PIERANTI, O. P. (Orgs.). Estado e gestão pública: visões do Brasil contemporâneo. 2. ed. Rio de Janeiro: FGV, 2006. p. 133-158.

CUnhA, J. B.; BLANK, V. L. G.; BoING, A. F. Tendência temporal de afastamento do trabalho em servidores públicos (1995-2005). Revista Brasileira de Epidemiologia, São Paulo, v. 12, n. 2, p. 226-236, 2009.

DEJOURS, C. Uma nova visão do sofrimento humano nas organizações. In: CHANLAT, J. F. O indivíduo na organização: dimensões esquecidas. 2. ed. São Paulo: Atlas, 1993. v. 1. p. 149-173.

DiAs, E. C. et al. (Coord.). Políticas públicas de saúde: servidor público federal. Rio de Janeiro: Fiocruz, [2014]. Disponível em: <http://pt.slideshare.net/ GluciaSilveiraCastro/siass-projeto-final-diagramado-fadelfiocruz?redirected_ from=save_on_embed>. Acesso em: 10 set. 2014.

GUÉRIN, F. et al. Compreender o trabalho para transformá-lo: a prática da ergonomia. São Paulo: Blucher, Fundação Vanzolini, 2001.

INVESTIMENTO em saúde do servidor previne aposentadoria precoce. Contato: Boletim do Servidor, Brasília, n. 43, p. 2, 21 jan. 2005.

LAcombe, B. M. B.; Bendassolli, P. F. Cinco décadas de RH. Fator Humano. GV Executivo, São Paulo, v. 3, n. 3, p. 65-69, ago./out. 2004.

LHUILIER, D. Filiações teóricas das clínicas do trabalho. In: BENDASSOLLI, P. F.; SOBOLL, L. A. (Orgs.). Clínicas do trabalho: novas perspectivas para compreensão do trabalho na atualidade. São Paulo: Atlas, 2011. p. 22-58.

Marcelino, G. F. Em busca da flexibilidade do Estado: o desafio das reformas planejadas no Brasil. Revista de Administração Pública, Rio de Janeiro, v. 37, n. 3, p. 641-659, maio/jun. 2003. 
MARTINS, L. Reforma da administração pública e cultura política no Brasil: uma visão geral. Cadernos Enap, Brasília, n. 8, 1997.

Massardier, G. Redes de política pública. In: Saraiva, E.; Ferrarezi, E. (Orgs.). Políticas públicas. Brasília: Enap, 2006. (coletânea, 2 v.) p. 167-185.

Mınayo, M. C. S. O desafio do conhecimento: pesquisa qualitativa em saúde. 12 ed. São Paulo: Hucitec, 2010.

NUNES, A. V. L.; LINS, S. L. B. Servidores públicos federais: uma análise do prazer e sofrimento no trabalho. Revista Psicologia: Organização e Trabalho, Brasília, v. 9, n. 1, p. 51-67, jan./jun. 2009.

PAULA, A. P. P. Administração pública brasileira entre o gerencialismo e a gestão social. Revista de Administração de Empresas, São Paulo, v. 45, n. 1, p. 36-49, jan./ mar. 2005.

RAMMINGER, T.; NARDI, H. C. Saúde do trabalhador: um (não) olhar sobre o servidor público. Revista do Serviço Público, Brasília, v. 58, n. 2, p. 213-226, 2007. Disponível em: <http://seer.enap.gov.br/index.php/RSP/article/view/171/176>. Acesso em 03 nov. 2015.

RiBeiRo, C. V. S.; MANCEBo, D. O servidor público no mundo do trabalho do século XXI. Psicologia: Ciência e Profissão, Brasília, v. 33, n. 1, p. 192-207, 2013.

SALA, A. et al. Licenças médicas entre trabalhadores da Secretaria de Estado da Saúde de São Paulo no ano de 2004. Cadernos de Saúde Pública, Rio de Janeiro, v. 10, n. 25, p. 2168-2178, out. 2009.

SAÚDE do servidor: governo fará pesquisa para avaliar situação. Contato: Boletim do Servidor, Brasília, n. 19, p. 1, 3 nov. 2003.

SilvA, P. L. B.; Melo, M. A. B. O processo de implementação de políticas públicas no Brasil: características e determinantes da avaliação de programas e de projetos. Caderno NEPP, Unicamp, Campinas, n. 48, p. 1-16, 2000.

SISTEMA determina novas diretrizes para a saúde do servidor. Contato: Boletim do Servidor, Brasília, n. 62, p. 1, 4 dez. 2006.

SouZA, Z. B.; REIS, L. M. Entre o atender e o ser atendido: políticas em saúde para o trabalhador do serviço público. Cadernos de Psicologia Social do Trabalho, São Paulo, v. 16, n. 1, p. 87-106, 2013.

SZnelWAR, L. I; MASCIA, F. L.; BouYER, G. L'empêchement au travail: une source majeure de TMS? Activités, Paris, v. 3, n. 2, p. 28-44, 2006. Disponível em: <http:// www.activites.org/v3n2/LAERTE.pdf>. Acesso em: 19 out. 2014.

VILELA, R. A. G.; Silva, R. C.; Jackson Filho, J. M. Poder de agir e sofrimento: estudo de caso sobre agentes comunitários de saúde. Revista Brasileira de Saúde Ocupacional, v. 35, n. 122, p. 289-302, 2010.

ZANIN, F. et al. Política de atenção à saúde e segurança do trabalho do servidor público no Brasil. Universidade e Sociedade, Brasília, p.86-95, fev. 2015. 


\section{José Marçal Jackson Filho}

Possui doutorado em Ergonomie pela Conservatoire National des Arts et Métiers, França. Atualmente é Pesquisador da Fundação Jorge Duprat Figueiredo de Segurança e Medicina do Trabalho (Fundacentro). Contato: jose.jackson@fundacentro.gov.br

\section{Tarsila Baptista Ponce}

Possui mestrado em Trabalho, Saúde e Ambiente pela Fundação Jorge Duprat Figueiredo de Segurança e Medicina do Trabalho (Fundacentro). Atualmente é Analista em Ciência e Tecnologia na Fundacentro. Contato: tarsila.ponce@fundacentro.gov.br 